\title{
FAKTOR-FAKTOR YANG BERHUBUNGAN DENGAN PSYCHOLOGICAL WELL-BEING REMAJA SMP NEGERI 1 BANGUNTAPAN BANTUL YOGYAKARTA
}

\author{
Supriyadi $^{1}$, I Made Moh. Yanuar Saifudin, ${ }^{2}$ Burhanudin Hartono ${ }^{3}$ \\ ${ }^{1,2,3}$ Program Studi Keperawatan STIKes Surya Global Yogyakarta \\ yanuar.ikadek@gmail.com
}

\begin{abstract}
Abstrak
Remaja sebagai aset bangsa merupakan masa peralihan dari anak-anak kedewasa. Masa peralihan ini sering memunculkan permasalahan seperti kenakalan remaja. Kenakalan terjadi karena rehdahnya psychological wellbeing sehingga remaja tidak mampu beradaptasi pada masa perkembangannya dengan baik. psychological wellbeing dipengaruhi oleh jenis kelamin, usia, spiritualias dan tipe kepribadian. Tujuan studi ini adalah untuk mengetahui faktor-faktor yang berhubungan dengan psychological well-being remaja di SMP Negeri 1 Banguntapan Bantul Yogyakarta. Desain penelitian yang digunakan adalah penelitian deskriptif korelasi dengan pendekatan cross sectional. Populasi dalam penelitian ini adalah remaja di SMP Negeri 1 Banguntapan Bantul Yogyakarta. Teknik pengambilan sampel yang digunakan adalah purposive sampling didapatkan sample sebanyak 58 orang. Analisis data menggunakan uji statistik chi square. Hasil penelitian menunjukkan korelasi jenis kelamin $(\mathrm{p}=766)$, usia $(\mathrm{p}=0.030)$, spiritualitas $(\mathrm{p}=0.000)$ dan tipe kepribadian $(\mathrm{p}=0.015)$ dengan psychological well-being remaja di SMP Negeri 1 Banguntapan Bantul Yogyakarta.
\end{abstract}

Kata Kunci : psychological well-being, spiritualitas dan tipe kepribadian

\begin{abstract}
The factors related to psychological well-being Teenagers in SMP Negeri 1 Banguntapan Bantul Yogyakarta. Teenagers as a national asset is a transitional period from children to adulthood. This transitional period often raises problems such as juvenile delinquency. Delinquency occurs because of their rehdah psychological wellbeing so that adolescents are unable to adapt well during their developmental period. psychological well-being is influenced by gender, age, spirituality and personality type. The purpose of this study was to determine the factors related to the psychological well-being of adolescents in SMP Negeri 1 Banguntapan Bantul Yogyakarta. The research design used was a descriptive correlation study with a cross sectional approach. The population in this study were adolescents at SMP Negeri 1 Banguntapan Bantul Yogyakarta. The sampling technique used was purposive sampling and obtained a sample of 58 people. Data analysis used chi square statistical test. The results showed the correlation between gender $(p=766)$, age $(p=0.030)$, spirituality $(p=0.000)$ and personality type $(p$ $=0.015)$ with the psychological well-being of adolescents in SMP Negeri 1 Banguntapan Bantul Yogyakarta.
\end{abstract}

Keywords: personality types, spirituality and psychological well-being

\section{Pendahuluan}

Remaja sebagai aset bangsa merupakan masa peralihan dari anak-anak kedewasa. Masa peralihan ini sering memunculkan permasalahan seperti kenakalan remaja. Kenakalan remaja adalah perilaku jahat atau kenakalan anak-anak muda, merupakan gejala sakit (patologis) secara tingkah laku yang tidak dapat diterima sosial sampai pelanggaran status hingga tindak pidana (Kartono, 2014 ). Fenomena kenakalan remaja yang membuat resah masyarakat di Yogyakarta adalah klitih.
Klithih kalau menurut orang Jawa adalah mencari angin. Namun saat ini sudah berkembang menjadi kekerasan. Klithih sudah menjadi ruang apresiasi diri atas rasa bangga remaja di hadapan kerumunan teman sebaya. Klitih mayoritas dipengaruhi oleh faktor-faktor biologis, psikologis dan lingkungan sosial maupun spiritual dan psikososial (Pratiti, 2018).

Kekerasan klitih berupa aksi kekerasan dengan senjata tajam atau tindaktanduk kriminal anak di bawah umur di luar kelaziman. Pada tahun 2019 terjadi 40 kasus klitih dengan 81 orang sebagai pelaku. Dimana dari pelaku tersebut 57 
orang berstatus pelajar dan sisanya pengangguran. Modus klitih berupa penganiayaan 19 kasus, penggunaan senjata tajam 17 kasus dan disertai perusakan 4 kasus (Suhendar, 2020).

Kenakalan remaja menunjukkan menunjukkan rendahnya psychological well-being pada remaja. Terdapatnya psychological well-being yang baik dalam diri individu, khususnya remaja akan membuat dirinya mampu bertahan dan berkembang di masa peralihan yang sedang dihadapi. Psychological well-being menurut Ryff merupakan realisasi dan pencapaian penuh dari potensi individu, dimana individu dapat menerima segala kekurangan maupun kelebihan dirinya, mandiri, mampu membina hubungan yang positif dengan orang lain dan dapat menguasai lingkungan dengan kata lain mampu menciptakan lingkungan agar sesuai dengan keinginannya, memiliki tujuan hidup serta mengembangkan pribadinya (Munthe, Maslihah, \& Chotidjah, 2017).

Psychological well-being dapat dijadikan strategi untuk menyelesaikan permasalahan kenakalan remaja. Berdasrkan penelitian terdapat pengaruh psychoeducation psychological well-being terhadap kenakalan remaja dengan signifikansi sebesar $\mathrm{p}=0,000 \quad(\mathrm{p}<0,05)$ (Sari, 2017). Ryff menyatakan bahwa seseorang yang jiwanya sejahtera apabila ia tidak sekedar bebas dari tekanan atau masalah mental yang lain. Namun, lebih dari itu ia juga memiliki penilaian positif terhadap dirinya dan mampu bertindak secara otonomi serta tidak mudah hanyut oleh pengaruh lingkungan (Sari, 2017). Lyubomirsky et.al menampaikan psychological well being merupakan unsur penting yang perlu ditumbuhkan pada individu agar dapat menguatkan keterikatan secara penuh dalam menghadapi tanggung jawab dan mencapai potensinya (Hardjo, Aisyah, \& Mayasari, 2020).

Liputo dalam penelitiannya menyampaikan psychological well-being dipengaruhi berbagai faktor yaitu usia, jenis kelamin dan status sosial ekonomi, dukungan sosial, kompetensi pribadi, religiusitas, dan kepribadian (Batubara A. , 2017). Hasil penelitian menunjukkan ada korelasi yang signifikan antara spiritualitas dan psychological well-being $(\mathrm{r}=0.570$; $\mathrm{p}=0.00$ ) (Munthe, Maslihah, \& Chotidjah, 2017).

Berdasarkan hasil penelitian dan literature menunjukkan psychological wellbeing dapat dijadikan strategi untuk menyelesaikan kenakalan remaja maka peneliti tertarik melakukan penelitian dengan tujuan untuk mengetahui faktorfator yang berhubungan dengan psychological well-being remaja di SMP Negeri 1 Banguntapan Bantul Yogyakarta.

\section{Metode}

Penelitian ini merupakan jenis penelitian kuantitatif dengan desain deskriptif korelasional dengan tujuan menemukan ada tidaknya hubungan jenis kelamin, usia, spiritualitas dan tipe kepribadian dengan psychological wellbeing remaja di SMP Negeri 1 Banguntapan Bantul Yogyakarta. Sedangkan pendekatan yang digunakan adalah cross-sectional.

Teknik pengambilan sampel adalah purposive sampling yaitu pengembilan sampel yang ditetapkan peneliti berdasarkan kriteria yang ditetapkan oleh peneliti didapatkan sample sebanyak 58 orang. Analisis data menggunakan uji statistik chi square dengan tingkat signifikansi $5 \%$. Data primer didapatkan langsung dari responden dengan alat berupa kuesioner yaitu spiritualitas, tipe kepribadian dan Ryff's psychological wellbeing scale.

\section{Hasil}

1. Karakteristik, spiritualitas, tipe kepribadian dan psychological wellbeing pada remaja SMP Negeri 1 Banguntapan Bantul Yogyakarta.

Uji univariat menggunakan statistik deskriptif dilakukan untuk mengetahui gambaran tiap variabel 
dalam bentuk frekuensi dan persentase.

Secara detail hasil analisis disajikan

dalam tabel berikut:

Tabel 1 hasil uji univariat karakteristik, religiusitas, tipe kepribadian dan psychological well-being pada remaja SMP Negeri 1 Banguntapan

Bantul Yogyakarta

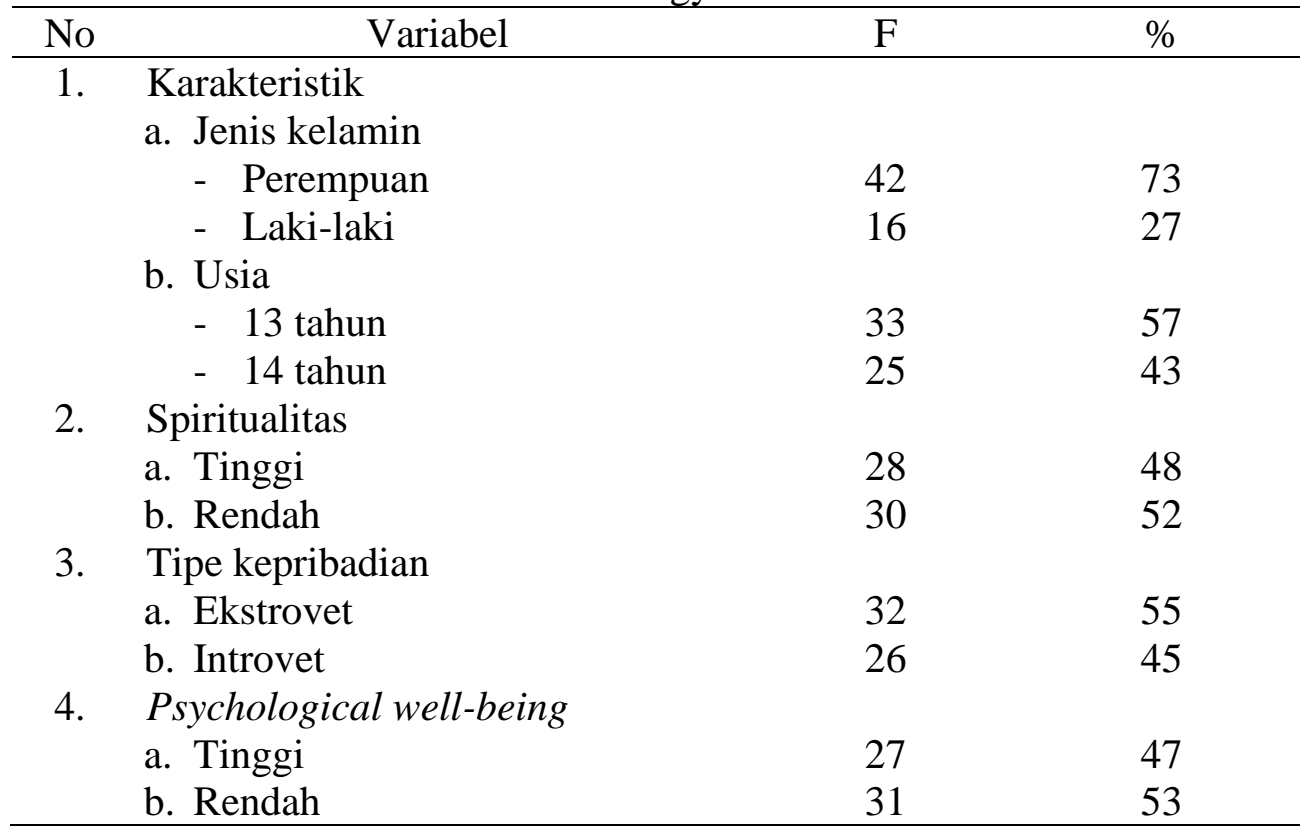

Berdasarkan tabel 1 menjelaskan karakteristik responden mayoritas perempuan $42(73 \%)$ dengan usia 13 tahun 33 (57\%). Sedangkan mayoritas untuk variabel spiritualitas dalam kategori rendah $30 \quad(52 \%)$, tipe kepribadian ekstrovet $32(55 \%)$ dan psychological well-being rendah 31 $(53 \%)$.

2. Hubungan jenis kelamin dengan psychological well-being pada remaja SMP Negeri 1 Banguntapan Bantul Yogyakarta.

Tabel 2 Tabulasi silang dan hasil uji korelasi antara jenis kelamin dengan psychological well-being remaja di SMP Negeri 1 Banguntapan Bantul Yogyakarta

\begin{tabular}{llllll}
\hline & & \multicolumn{2}{c}{ Psychological well-being } & \multirow{2}{*}{ Total } & \multirow{2}{*}{ p-Value } \\
\cline { 3 - 5 } & & \multicolumn{1}{c}{ Tinggi } & Rendah & & \\
\hline Jenis & Laki-laki & $10(63 \%)$ & $6(37 \%)$ & $16(100 \%)$ & \multirow{2}{*}{0.766} \\
Kelamin & Perempuan & $17(40 \%)$ & $25(60 \%)$ & $42(100 \%)$ & \\
\hline
\end{tabular}

Berdasarkan tabel 2 menunjukkan nilai $p$-value sebesar 0.766 $(>0.05)$, yang berarti tidak terdapat hubungan yang signifikan antara jenis kelamin dengan psychological well-
Uji bivariat menggunakan chi sguare dilakukan bertujuan untuk mengetahui hubungan antara jenis kelamin dengan psychological wellbeing remaja di SMP Negeri 1 Banguntapan Bantul Yogyakarta. 
responden memiliki psychological well-being tinggi dan $25(60 \%)$ responden rendah. Dari 16 responden berjenis kelamin laki-laki 10 (63\%) memiliki psychological well-being tinggi dan $6(37 \%)$ responden rendah.
Uji bivariat menggunakan chi square dilakukan bertujuan untuk mengetahui hubungan antara usia dengan psychological well-being remaja di SMP Negeri 1 Banguntapan Bantul Yogyakarta.

3. Hubungan usia dengan psychological well-being pada remaja SMP Negeri 1 Banguntapan Bantul Yogyakarta.

Tabel 3 Tabulasi silang dan hasil uji korelasi antara usia dengan psychological well-being remaja di SMP Negeri 1

Banguntapan Bantul Yogyakarta

\begin{tabular}{llllll}
\hline & & \multicolumn{2}{c}{ Psychological well-being } & \multirow{2}{*}{ Total } & \multirow{2}{*}{ p-Value } \\
\cline { 3 - 5 } & \multicolumn{2}{c}{ Tinggi } & \multicolumn{1}{c}{ Rendah } & & \\
\hline Usia & 13 Tahun & $7(21 \%)$ & $26(79 \%)$ & $33(100 \%)$ & \multirow{2}{*}{0.023} \\
& 14 Tahun & $20(80 \%)$ & $5(20 \%)$ & $25(100 \%)$ & \\
\hline
\end{tabular}

Berdasarkan tabel 3 menunjukkan nilai p-value sebesar $0.023(<0.05)$, yang berarti terdapat hubungan yang signifikan antara usia dengan psychological well-being remaja di SMP Negeri 1 Banguntapan Bantul Yogyakarta.

Tabel tabulasi silang menunjukkan 33 responden yang berusia 13 tahun terdapat $7(21 \%)$ responden memiliki psychological well-being yang tinggi dan 26 (79\%) responden rendah. Kemudian responden yang berusia 14 tahun memiliki psychological well-being kategori tinggi sebanyak $20(80 \%)$ responden dan 5 (20\%) rendah.

4. Hubungan spiritualitas dengan psychological well-being remaja di SMP Negeri 1 Banguntapan Bantul Yogyakarta.

Uji bivariat menggunakan chi square dilakukan bertujuan untuk mengetahui hubungan antara spiritualitas dengan psychological wellbeing remaja di SMP Negeri 1 Banguntapan Bantul Yogyakarta.

Tabel 4 Tabulasi silang dan hasil uji korelasi antara spiritualitas dengan psychological well-being remaja di SMP Negeri 1

Banguntapan Bantul Yogyakarta

\begin{tabular}{llllll}
\hline & & \multicolumn{2}{c}{ Psychological well-being } & \multirow{2}{*}{ Total } & \multirow{2}{*}{ p-Value } \\
\cline { 2 - 4 } & & Tinggi & Rendah & & \\
\hline \multirow{2}{*}{ Spiritualitas } & Tinggi & $15(54 \%)$ & $13(46 \%)$ & $28(100 \%)$ & \multirow{2}{*}{0.000} \\
& Rendah & $12(40 \%)$ & $18(60 \%)$ & $30(100 \%)$ & \\
\hline
\end{tabular}

Berdasarkan tabel 4 menunjukkan nilai p-value sebesar $0.000(<0.05)$, yang berarti terdapat hubungan yang signifikan antara spiritualitas dengan psychological wellbeing remaja di SMP Negeri 1 Banguntapan Bantul Yogyakarta.
Tabulasi silang menunjukkan bahwa dari 28 100\%) remaja yang memiliki spiritualitas tinggi terdapat 15 (54\%) remaja yang memiliki psychological well-being tinggi dan 13 $(46 \%)$ rendah. Sedangkan dari 30 $(100 \%)$ remaja dengan spiritualitas 
rendah terdapat $12(40 \%)$ memiliki psychological well-being tinggi dan 18 $(60 \%)$ rendah.

5. Hubungan tipe kepribadian dengan psychological well-being remaja di SMP Negeri 1 Banguntapan Bantul Yogyakarta.
Uji bivariat menggunakan chi sguare dilakukan bertujuan untuk mengetahui hubungan antara tipe kepribadian dengan psychological well-being remaja di SMP Negeri 1 Banguntapan Bantul Yogyakarta.

Tabel 5 Tabulasi silang dan hasil uji korelasi antara tipe kepribadian dengan psychological well-being remaja di SMP Negeri 1 Banguntapan

\begin{tabular}{|c|c|c|c|c|c|}
\hline \multicolumn{6}{|c|}{ Bantul Yogyakarta } \\
\hline & & \multicolumn{2}{|c|}{ Psychological well-being } & \multirow{2}{*}{ Total } & \multirow{2}{*}{ p-Value } \\
\hline & & Tinggi & Rendah & & \\
\hline Jenis & Ekstrovet & $14(44 \%)$ & $18(56 \%)$ & $32(100 \%)$ & \multirow{2}{*}{0.015} \\
\hline Kelamin & Introvet & $13(50 \%)$ & $13(50 \%)$ & $26(100 \%)$ & \\
\hline
\end{tabular}

Berdasarkan table 5 menunjukkan nilai $\mathrm{p}$-value sebesar 0.015 $(<0.05)$, yang berarti terdapat hubungan yang signifikan antara tipe kepribadian dengan psychological well-being pada remaja di SMP Negeri 1 Banguntapan Bantul Yogyakarta.

Tabulasi silang menunjukkan bahwa dari 32 (100\%) remaja yang memiliki tipe kepribadian ekstrovet terdapat 14 (44\%) remaja yang memiliki psychological well-being tinggi dan 18 (56\%) rendah. Sedangkan dari 26 (100\%) remaja dengan tipe kepribadian introvet terdapat $13 \quad(50 \%)$ memiliki psychological well-being tinggi dan 13 (50\%) rendah.

\section{Pembahasan}

1. Hubungan jenis kelamin dengan psychological well-being pada remaja SMP Negeri 1 Banguntapan Bantul Yogyakarta.

Hasil penelitian didapatkan berdasarkan jenis kelamin psychological well-being mayorita dalam kategori rendah pada perempuan $25(43 \%)$ responden. Hasil uji statistik menunjukkan $p$-value 0.766 ( $>0.005)$. Hal tersebut menunjukkan tidak ada hubungan antara jenis kelamin dengan psychological well-being pada remaja
SMP Negeri 1 Banguntapan Bantul Yogyakart.

Hasil penelitian ini sesuai dengan hasil penelitian yang menyatakan jenis kelamin tidak ditemukan perbedaan skor kesejahteraan psikologis yang signifikan bagi siswa lakilaki dan perempuan (Ramadhani, Djunaedi, \& $\mathrm{S}, 2016)$. Nilai sig. $\mathrm{p}=0,2325(\mathrm{p}>0,05)$ yang berarti tidak terdapat perbedaan tingkat kesejahteraan psikologis ditinjau dari jenis kelamin (Putri, 2019)

2. Hubungan usia dengan psychological well-being pada remaja SMP Negeri 1 Banguntapan Bantul Yogyakarta.

Hasil dalam penelitian ini menunjukkan bahwa psychological well-being pada remaja SMP Negeri 1 Banguntapan Bantul Yogyakarta dalam kategori tinggi sebanyak 27 (37\%) responden dan rendah sebanyak 31 $(53 \%)$ responden. Berdasarkan data tersebut dapat disimpilkan bahwa psychological well-being pada remaja SMP Negeri 1 Banguntapan Bantul Yogyakarta mayoritas dalam kategori rendah.

Rendahnya psychological wellbeing pada remaja SMP Negeri 1 Banguntapan Bantul Yogyakarta, salah satunya dikarenakan faktor usia dimana responden dalam penelitian ini 
sejumlah 58 (100\%) berusia 13-14 tahun. Hal ini sesuai teori Ryff bahwa terdapat peningkatan psychological well-being pada usia yang semakin dewasa (Liwarti, 2013).

Hasil penelitian ini menunjukkan bahwa usia menjadi salah satu faktor yang memiliki hubungan dengan psychological well-being pada remaja di SMP Negeri 1 Banguntapan Bantul Yogyakarta. Hal tersebut ditunjukkan melalui hasil analisis statistik, pada remaja di SMP Negeri 1 Banguntapan Bantul Yogyakarta hasil dari uji korelasi antara spiritualitas dengan psychological well-being yakni nilai $\mathrm{p}$ sebesar 0,023 $(\mathrm{P}<0,05)$.

Hasil penelitian ini sesuai dengan Ryff menyampaikan faktor demografis yang mempengaruhi kesejahteraan psikologis (psychological well-being) yaitu usia, jenis kelamin, status sosial ekonomi, dan budaya (Ramadhani, Djunaedi, \& S, 2016). Fitri et.al menyampaikan faktor-faktor yang mempengaruhi pembentukan kesejahteraan psikologis diantaranya usia, gender, status sosialekonomi, pendidikan, budaya, religiusitas, kepribadian dan dukungan social (Armanda \& Fithria, 2018).

3. Hubungan spiritualitas dengan psychological well-being remaja di SMP Negeri 1 Banguntapan Bantul Yogyakarta.

Hasil penelitian didapatkan spiritualitas dalam kategori tinggi 28 (48\%) dan rendah 30 (52\%). Dapat disimpulkan mayoritas spiritualitas remaja SMP Negeri 1 Banguntapan Bantul Yogyakarta yaitu rendah. Hasil penelitian ini hampir sama dengan penelitian lain dengan hasil psychological well-being remaja di lembaga pendidikan pesantren dan non-pesantren mayaritas dalam kategori sedang yaitu $29 \quad(65 \%)$ responden (Lisnawati \& Rahmah, 2018).
Hasil penelitian ini menunjukkan bahwa spiritualitas menjadi salah satu faktor yang memiliki hubungan dengan psychological well-being pada remaja di SMP Negeri 1 Banguntapan Bantul Yogyakarta. Hal tersebut ditunjukkan melalui hasil analisis statistik, pada remaja di SMP Negeri 1 Banguntapan Bantul Yogyakarta hasil dari uji korelasi antara spiritualitas dengan psychological well-being yakni nilai $\mathrm{p}$ sebesar 0,000 $(\mathrm{P}<0,05)$.

Hasil uji tabulasi silang juga menunjukkan remaja yang memiliki spiritualitas yang tinggi juga memiliki psychological well-being yang tinggi. dari $28(100 \%)$ remaja yang memiliki spiritualitas tinggi terdapat $15(54 \%)$ remaja yang memiliki psychological well-being tinggi dan 13 (46\%) rendah.

Psychological well-being sesorang salah satunya dipengaruhi oleh spiritualitas. Spiritual dan keyakinan keagamaan merupakan salah satu komponen penting dalam membangun kehidupan yang bermakna dalam sisi psikologis seseorang (Lisnawati \& Rahmah, 2018).

Hasil penelitian ini sesuai dengan penelitian lain yang menyatakan terdapat hubungan yang signifikan antara spiritualitas dengan psychological well-being dengan nilai $\mathrm{r}$ sebesar 0,794 dan nilai p sebesar 0,000 dan Munthe dkk (2017). nilai r sebesar 0,570 dan nilai $\mathrm{p}$ sebesar 0,000 (Lisnawati \& Rahmah, 2018).

Remaja yang memiliki kesejahteraan psikologis yang baik, akan meningkatkan kehidupan yang lebik baik dimana ia memiliki kesadaran akan potensi dan kekurangan yang ia miliki, mampu menerima diri apa adanya, mampu mengembangkan eksistensi di masyarakat, dan lain sebagainya (Aflakseir, 2012)

4. Hubungan tipe kepribadian dengan psychological well-being remaja di 
SMP Negeri 1 Banguntapan Bantul Yogyakarta.

Dalam penelitian ini mayoritas tipe kepribadian ekstravert yaitu 32 (55\%) responden. Psychological wellbeing merupakan suatu kondisi tertinggi yang dapat dicapai oleh individu yang mencakup evaluasi dan penerimaan diri pada berbagai aspek kehidupan tidak hanya berupa aspek positif namun juga aspek negatif yang terbagi dalam enam dimensi, yaitu: dimensi penerimaan diri, dimensi hubungan positif dengan orang lain, dimensi otonomi, dimensi penguasaan lingkungan, tujuan hidup dan dimensi pengembangan pribadi (Lakoy, 2015).

Psychological well-being salah satunya di pengaruhi oleh tipe kepribadian. Hal ini dibuktikan dari hasil penelitian pada remaja di SMP Negeri 1 Banguntapan Bantul Yogyakarta yang bertujuan mencari hubungan antara tipe kepribadian dengan psychological well-being didapatkan nilai $\mathrm{p}$ sebesar $0,015(\mathrm{P}<$ $0,05)$.

Hal ini sejalan dengan teori dikatakan oleh Lisnawati bahwa psychological well-being sesorang salah satunya dipengaruhi oleh tipe kepribadian. Responden pada penelitian ini remaja yang memiliki usia 13-14 tahun dimana dalam usia ini merupakan masa perkembengan dan tantangan baik secara fisik maupun psikologis termasuk kepribadian (Lisnawati \& Rahmah, 2018)

Meskipun kepribadian seseorang itu relative konstan, namun kenyataan sering ditemukan dilapangan adalah adanya perubahan kepribadian. Perubahan tersebut ternyata disebabkan oleh gangguan fisik dan lingkungan dimana individu itu berada. Faktor yang menyebabkan terjadinya perubahan kepribadian tersebut antara lain: 1). Faktor fisik, seperti gangguan otak, kurang gizi, mengkonsumsi obatobatan terlarang atau NARKOBA, minuman keras, dan gangguan ortanik (sakit atau kecelakaan). 2). Faktor lingkungan sosial budaya, seperti krisi politik, ekonomi, dan keamanan yang mcnyebabkan terjadinya masalah pribadi (stres dan depresi) dan masalah sosial (pcngangguran, premanisme, kriminalitas). 3. Faktor diri sendiri, seperti tekanan emosional, frustasi yang berkepanjangan, dan identifikasi atau imitasi terhadap orang lain yang berkepribadian menyimpang.

Dalam penelitian ini mayoritas tipe kepribadiannya adalah ekstravert 32 (55\%). Tipe kepribadian yang tindakannya dipengaruhi dunia luar, bersifat terbuka, lincah dalam pergaulan, riang, ramah, mudah berhubungan dengan orang lain, melihat realistis dan keharusan, kebal terhadap kritik, ekspresi emosinya spontan, tidak begitu merasakan kegagalan, serta tidak banyak mengadakan analisis dan kritik diri sendiri.

Orang ekstrover itu mudah bersosialisasi, senang hura-hura, mempunyai banyak teman, membutuhkan orang untuk diajak bicara, tidak suka membaca atau belajar sendiri, butuh kegembiraan, berani ambil risiko, selalu mempertahankan pendapatnya, bertindak tanpa dipikir dulu, menurutkan kata hati (impulsif), suka melawak, selalu mempunyai jawaban yang segar dan umumnya menyukai perubahan, periang, supel, optimis, dan senang tertawa. Mereka lebih suka bergerak dan melakukan kegiatan, cenderung agresif, mudah kehilangan kesabaran. Secara keseluruhan, perasaanya sulit untuk dijaga dan dia tidak selalu dapat dipercaya (Tarmidzi, 2012)

\section{Simpulan dan Saran}

Remaja di SMP Negeri 1 Banguntapan Bantul Yogyakarta mayoritas memiliki spiritualitas rendah, tipe 
kepribadian ekstravert dan psychological well-being juga rendah. Variabel yang memiliki hubungan dengan psychological well-being pada remaja di SMP Negeri 1 Banguntapan Bantul Yogyakarta adalah usia, spiritualitas dan tipe kepribadian. Sedangkan jenis kelamin tidak ada hubungannya dengan psychological wellbeing pada remaja di SMP Negeri 1 Banguntapan Bantul Yogyakarta.

Hasil penelitian ini dapat dijadikan pedoman guru untuk mengembang program kegiatan spiritual sehingga meningkatkan psychological well-being bagi siswanya. Peneliti selanjutnya dapat memberikan intervensi yang dapat meningkatkan psychological well-being.

\section{Daftar Pustaka}

Aflakseir, A. (2012). Religiosity, personal meaning, and psychological wellbeing: a study among muslim students in England. Pakistan Journal of Social and Clinical Psychology, Vol. 9, No. 2. Retrieved from https://www.questia.com/library/jou rnal/1P3-2680657691/religiositypersonal-meaning-andpsychological-well-being.

Armanda, C. D., \& Fithria. (2018). Psychological well-being pada remaja laki-laki di sekolah menengah atas. JIM FKep, Vol. III, No. 3. Retrived from http://jim.unsyiah.ac.id/FKep/article /view/8275/5154.

Batubara, A. (2017). Hubungan antara religiusitas dengan psychological well being ditinjau dari big five personality pada siswa SMA Negeri 6 Binjai. AL-Irsyad: Jurnal Pendidikan dan Konseling, Vol. 7, No. 1, 48-62. Retrieved from http://jurnal.uinsu.ac.id/index.php/al -irsyad/article/view/6667/2919.

Batubara, L. c. (2017). Hubungan Antara Religiusitas Dengan Psychological Well Being Ditinjau Dari Big Five Personality Pada Siswa SMA
Negeri 6 Binjai. Al-Irsyad: Jurnal Pendidikan Dan Konseling, Vol 7, No 1, PP 48-62 http://jurnal.uinsu.ac.id/index.php/al -irsyad/article/view/6667.

Hardjo, S., Aisyah, S., \& Mayasari, S. I. (2020). Bagaimana psychological well being pada remaja? sebuah analisis berkaitan dengan faktor meaning in life. Jurnal Diversita, DOI: 10.31289/diversita.v6i1.2894.

Kartono, K. (2014 ). Patologi sosial 2 kenakalan remaja. Jakarta: Raja Grafindo.

Lakoy, F. S. (2015). Psychological wellbeing perempuan bekerja dengan status menikah dan belum menikah. Repository UEU, Retrieved from: https://digilib.esaunggul.ac.id/psych ological-wellbeing-perempuanbekerjadengan-status-menikah-danbelum-menikah-4997.html.

Lisnawati, \& Rahmah, I. A. (2018). Kesejahteraan psikologis ditinjau dari spiritualitas siswa di lembaga pendidikan berbasis agama pesantren dan non pesantren. Jurnal Psikologi Integratif, Vol 6, No 2, DOI:

https://doi.org/10.14421/jpsi.v6i2.1 499.

Liwarti. (2013). Hubungan pengalaman spiritual dengan psychological well being pada penghuni lembaga pemasyarakatan. Psychological Journal: Science and Practice, Vol. 1, No. 1. Retrieved from http://ejournal.umm.ac.id/index.php /pjsp/article/view/1350.

Munthe, B. E., Maslihah, S., \& Chotidjah, S. (2017). Hubungan spiritualitas dan psychological well-being pada anak didik pemasyarakatan di lembaga pemasyarakatan anak pria kelas IIA Tangerang. Jurnal Psikologi Klinis Indonesia, Vol 1, No 1, 53-65. Retrieved from https://jurnal.ipkindonesia.or.id/inde x.php/jpki/article/view/5. 
Pratiti, B. (2018). Kekerasan Remaja Indonesia Mencapai 50 Persen. Yogyakarta: FKKMK UGM https://fk.ugm.ac.id/kekerasanremaja-indonesia-mencapai-50persen/.

Putri, L. H. (2019). Perbedaan tingkat kesejahteraan psikologis remaja di panti asuhan ditinjau dari jenis kelamin. Naskah Publikasi UMS, Retrieved from http://eprints.ums.ac.id/74222/1/NA SKAH\%20PUBLIKASI.pdf.

Ramadhani, T., Djunaedi, D., \& S, A. S. (2016). Kesejahteraan psikologis (psychological well-being) siswa yang orangtuanya bercerai. Insight: Jurnal Bimbingan dan Konseling , Vol 5, No 1, 108-115. DOI: https://doi.org/10.21009/INSIGHT. 051.16.

Sari, I. N. (2017). Psychoeducation psychological well being dan kenakalan remaja. Persona: Jurnal Psikologi Indonesia, Vol. 6, No.1, 31-38. Retrieved from http://jurnal.untagsby.ac.id/index.php/persona/article/ view/1628/1388.

Suhendar, A. (2020). Polda DIY Tangani 40 Kasus Klitih Setahun Terakhir. Yogyakarta: IDN Times Jogja https://jogja.idntimes.com/news/jogj a/tunggul-damarjati/polda-diytangani-40-kasus-klitih-setahunterakhir/3.

Tarmidzi, D. S. (2012). Tarmidzi, D. S. (2012). Hubungan antara Tipe Kepribadian: Ekstrovert dan Introvert dengan Prestasi Akademik Mahasiswa Fakultas Teknik Universitas Indonesia Program S1 Reguler. . Skripsi. Jakarta: Universitas Indonesia., http://lib.ui.ac.id/file?file=digital/20 311983-S43436-

Hubungan\%20antara.pdf. 